\title{
Primary Cutaneous Mucinous Carcinoma of the Abdomen
}

\author{
Kazunori Miyata, Usho Go, Takashi Oide ${ }^{1}$, Tsuyoshi Mitsuishi \\ Departments of Dermatology and ${ }^{1}$ Pathology, Tokyo Women's Medical University Yachiyo Medical Center, Yachiyo, Japan
}

\section{Dear Editor:}

Primary cutaneous mucinous carcinoma (PCMC) is a rare malignant tumor which usually appears on the periocular region and mimics metastatic skin carcinoma ${ }^{1,2}$. We have encountered a case of PCMC that appeared on the abdomen.

A 72-year-old male presented with an asymptomatic nodular lesion on his right lower abdomen. He first noticed the nodular lesion approximately 2 years ago. Clinical examination revealed a slight reddish surface colored, elastic hard nodule, measuring approximately $2 \mathrm{~cm}$, on his right lower abdomen (Fig. 1). The regional lymph nodes were not involved. The skin lesion was completely resected under local anesthesia and the margins were free of tumor in this case. Microscopic examination revealed numerous small tumor cell islands with pools of mucinous materials in the dermis (Fig. 2A). Alcian blue staining of mucin was positive at $\mathrm{pH} 2.5$ (Fig. 2B). The numerous mucin also indicated positive periodic acid-Schiff stain.

Immunohistochemical studies were performed on formalin-fixed, paraffin embedded tissue, using cytokeratin (CK) 7, 20, epithelioid membrane antigen (EMA), gross cystic disease fluid protein (GCDFP)-15, thyroid transcription factor 1 (TTF1), napsin A, and CDX2 antibodies. Among them, CK7, GCDFP-15, and EMA were predominantly stained in the tumor cells consist with islands (Fig. 2C, D). We received the patient's consent form about publishing all photographic materials.

PCMC is sometimes misdiagnosed as metastatic skin carcinoma, especially colon cancer, and lung cancer ${ }^{1,2}$. Therefore, internal malignancies should be ruled out since the subcutaneous lesion could represent metastatic skin tumor. Immunohistochemically, mostly the metastatic mucinous carcinoma of colon cancer indicated CK20 and CDX2 were stained in tumor cells $s^{3,4}$. In contrast, the metastatic carcinoma of lung cancer showed tumor cells were stained with CK7, TTF1 and napsin $A^{4,5}$. In our case, the tumor cells were negative for TTF1, napsin A, and CDX2. Furthermore, no distant metastasis was found by positron emission tomography Image, pelvic computed tomography, and chest X-P. Therefore, these findings supported diagnosis of PCMC.

Kamalpour et al. ${ }^{2}$ summarized one hundred fifty-nine cas-



Fig. 1. Clinical manifestation of the lesional skin. A 2-cm-diameter, slight reddish surface colored, elastic hard nodule on his right abdomen.

Received January 19, 2018, Revised April 11, 2018, Accepted for publication April 25, 2018

Corresponding author: Tsuyoshi Mitsuishi, Department of Dermatology, Tokyo Women's Medical University Yachiyo Medical Center, 477-96, Ohwada-Shinden, Yachiyo, Chiba 276-8524, Japan. Tel: 81-47-450-6000, Fax: 81-47-458-7047, E-mail: tmitsu@twmu.ac.jp ORCID: https://orcid.org/0000-0001-6696-5524

This is an Open Access article distributed under the terms of the Creative Commons Attribution Non-Commercial License (http://creativecommons.org/ licenses/by-nc/4.0) which permits unrestricted non-commercial use, distribution, and reproduction in any medium, provided the original work is properly cited.

Copyright (C) The Korean Dermatological Association and The Korean Society for Investigative Dermatology 

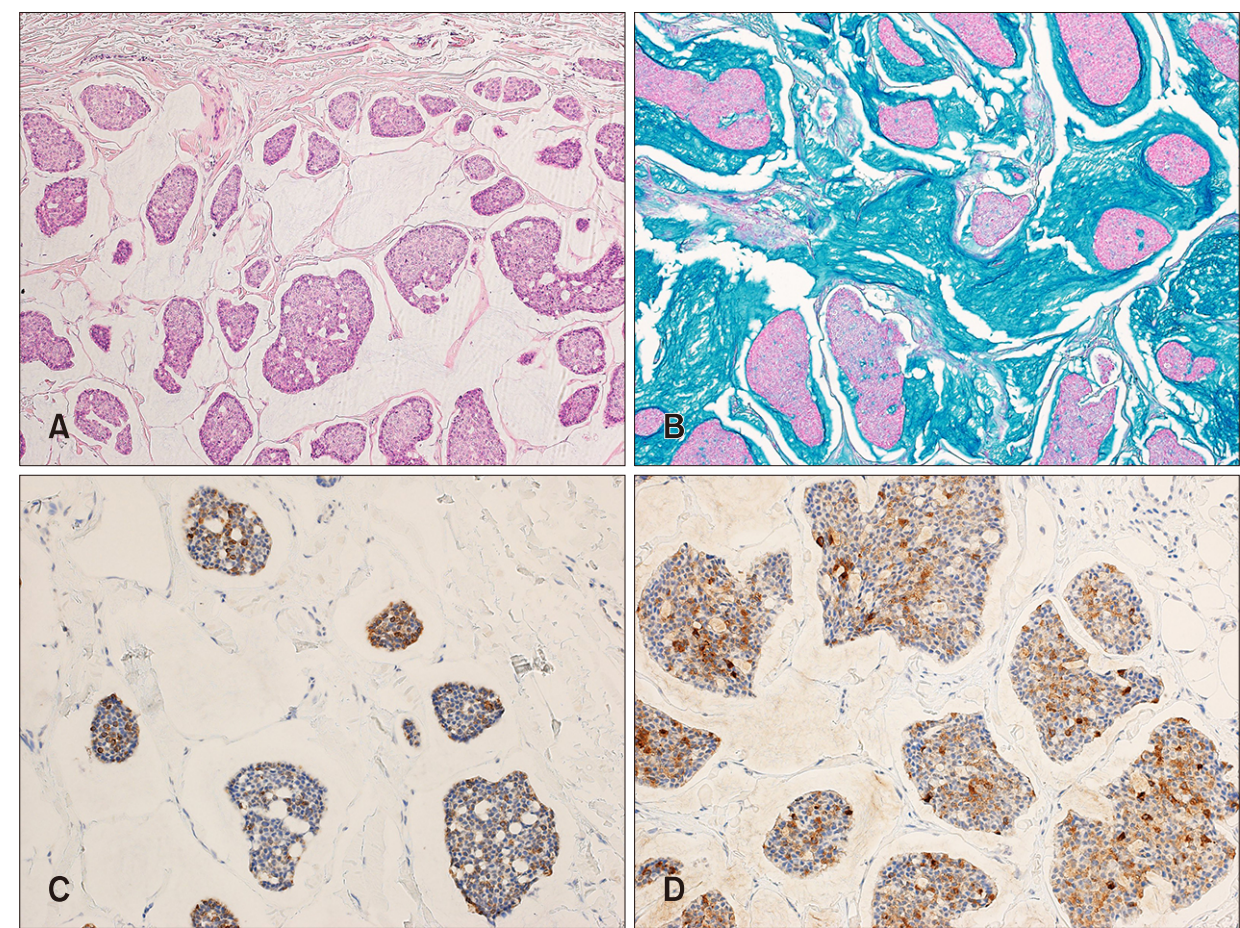

Fig. 2. Histopathological findings of the primary mucinous carcinoma of the skin. (A) Numerous small tumor cell islands in pools of mucinous materials in the dermis $(\mathrm{H} \& \mathrm{E}, \times 100)$. (B) Alcian blue staining of mucin was positive at $\mathrm{pH} 2.5$ $(\times 100)$. (C) Immunohistochemistry stains. Tumor cells were stained with cytokeratin $7(\times 100)$. (D) Gross cystic disease fluid protein-15 staining $(\times 200)$. es of PCMC, of which $86.2 \%(137 / 159)$ appeared on the head and neck. The eccrine sweat gland abundant lesion, such as axilla and genital areas are especially found.

However, it may occur other sites and its rate was 3.8\% (6/159). Breiting et al. ${ }^{4}$ reported 15 PCMC during 25 years. Among them, one PCMC appeared on the abdomen. Our case is also seen on the lower abdomen but not on the head and neck. It seemed to be appeared on the location of which no abundant sweat glands. Local recurrence occurs frequently about $30 \%$ to $40 \%$, but distant and lymph node metastases were rare and the rate is about $6 \%$. In addition, lesion location on the trunk compared to head and neck indicated bad outcome having recurrence or metastasis $^{2}$. PCMC is unclear what factor may lead to high local recurrent rate ${ }^{1,2}$. The patient had no evidence of local recurrence after a follow-up period of 2 years. Although the skin lesion was completely resected for this case, careful follow-up should be recommended.

\section{CONFLICTS OF INTEREST}

The authors have nothing to disclose.

\section{ORCID}

Kazunori Miyata, https://orcid.org/0000-0002-0607-1390
Usho Go, https://orcid.org/0000-0002-7357-3980

Takashi Oide, https://orcid.org/0000-0003-2944-9509

Tsuyoshi Mitsuishi, https://orcid.org/0000-0001-6696-5524

\section{REFERENCES}

1. Kim JB, Choi JH, Kim JH, Park HJ, Lee JS, Joh OJ, et al. A case of primary cutaneous mucinous carcinoma with neuroendocrine differentiation. Ann Dermatol 2010;22:472-477.

2. Kamalpour L, Brindise RT, Nodzenski M, Bach DQ, Veledar E, Alam M. Primary cutaneous mucinous carcinoma: a systematic review and meta-analysis of outcomes after surgery. JAMA Dermatol 2014;150:380-384.

3. Drew JE, Farquharson AJ, Mayer CD, Vase HF, Coates PJ, Steele RJ, et al. Predictive gene signatures: molecular markers distinguishing colon adenomatous polyp and carcinoma. PLoS One 2014;9:e113071.

4. Breiting L, Christensen L, Dahlstrøm K, Breiting V, Winther JF. Primary mucinous carcinoma of the skin: a populationbased study. Int J Dermatol 2008;47:242-245.

5. Ye J, Hameed O, Findeis-Hosey JJ, Fan L, Li F, McMahon LA, et al. Diagnostic utility of PAX8, TTF-1 and napsin A for discriminating metastatic carcinoma from primary adenocarcinoma of the lung. Biotech Histochem 2012;87:30-34. 